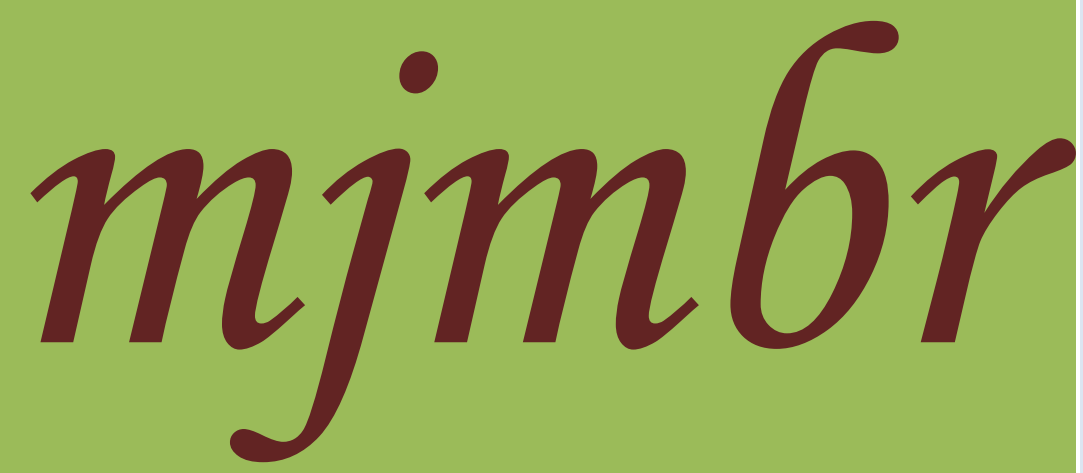

Malaysian Journal of Medical and Biological Research

www.jmbr-my.weebly.com

Vol 1, No. 1, 2014 


\title{
Ten years tuberculosis trend in Gambella Regional Hospital, South Western Ethiopia
}

\author{
Getahun Asebe ${ }^{1}$, Gobena Ameni ${ }^{2}$, \& Ketema Tafess ${ }^{3}$ \\ ${ }^{1}$ Aklilu Lemma Institute of Pathobiology, Addis Ababa University, Addis Ababa, Ethiopia \\ ${ }^{2}$ Gambella College of Agriculture, Gambella, Ethiopia \\ ${ }^{3}$ Armauer Hansen Research Institute, Addis Ababa, Ethiopia
}

\begin{abstract}
Background: Tuberculosis (TB) is a chronic infectious disease mainly caused by Mycobacterium tuberculosis (MTBC). It is one of the major health problems in Ethiopia, across the nation. According to World Health Organization 2009 report the status of TB in Gambella Region was the highest from all the Ethiopian Regions, with the notification rate of (new and relapse) 261-421/100, 000. We, therefore, carried out this study to investigate the trend of TB in Gambella Regional Hospital Southwest Ethiopia.

Methods: The study was conducted at the Gambella Regional Hospital, South Western Ethiopia. Retrospectively the medical records of all TB patients registered from $1^{\text {st }}$ January 2003 to $14^{\text {th }}$ November 2012 were assessed.

Results: The results of the study revealed that there were 4300 TB cases registered in the ten years duration in Gambella Regional Hospital. Males consist the highest percentage $2430(56.51 \%)$. Out of 4300 TB cases registered $1045(24.30 \%)$ had Extra pulmonary TB (EPTB) and $3255(75.70 \%)$ suffered from pulmonary TB (PTB) $\left(\chi^{2}=31\right.$. 14; $p<0.001)$. From 3255 registered PTB cases, smear positive PTB accounted for 1368 $(31.81 \%)$ of the cases. The age groups $15-44$ took the highest percentage among the patients 2918 (67.86\%). Only 1444 patients were knew their HIV status out of these 423 $(29.29 \%)$ were HIV positives. The trend in TB registered cases of all forms of TB was gradually declining in the ten years.

Conclusion: The retrospective study showed that TB problem in the study area was not at the level to be undermined. Hence, TB control program should give attention to the control of TB in Gambella Region.
\end{abstract}

Key words: Tuberculosis, Trend, Gambella, Southwestern, Ethiopia

crossref DOI: $10.15590 / \mathrm{mjmbr} / 2014 / \mathrm{v} 1 \mathrm{i1} / 53716$

License: CC-BY-NC

\section{BACKGROUND}

Tuberculosis (TB) is a chronic infectious disease mainly caused by Mycobacterium tuberculosis Complex (MTBC). The main source of infection is untreated smear-positive pulmonary TB (PTB) patient discharging the bacilli. It mainly spreads by an airborne route when the infectious patient expels droplets containing the bacilli. It is also transmitted by consumption of raw milk containing Mycobacterium bovis (M. bovis) (Harries and Dye, 2006; Palomino et al., 2007). It hinders socioeconomic development as $75 \%$ of people with TB are within the economically productive age group of 14-54 years. Researches and reports also indicates approximately $95 \%$ of all cases and $99 \%$ of deaths occur in developing countries, with the greatest burden in Sub-Saharan Africa (SSA) and South East Asia (Dye et al., 2005). 
Geographically, the TB burden is highest in Asia and Africa. India and China together account for almost $40 \%$ of the world's TB cases. The African Region has $24 \%$ of the world's cases and the highest rates of cases and deaths per capita. Almost $80 \%$ of TB cases among people living with HIV reside in Africa (WHO, 2012). The World Health Organization 2009 report indicated that the status of TB in Gambella Region was the highest from all the Ethiopian Regions, with the notification rate (new and relapse) 261-421/100, 000 (WHO, 2009). The Gambella Regional Hospital is one of the popular health delivery institution in the region that holds a total of the whole people of the region estimated to be 390, 593 population by the end of 2012 (CSA, 2012) and 44, 269 people visit in the hospital and gets service annually.

At present, the Gambella Regional Hospital gives diagnostic and treatment services for TB patients based on the direct observed treatment short course (DOTS) program. TB is one of the listed causes of mortality and morbidity in the area based on the hospital data and WHO reports. HIV/AIDS sero-prevalence indicators showed a gradual decline from year 2004 to 2010 from a prevalence of $4.3 \%$ to $2.8 \%$, which is found to be high, compared to other parts of the country. This study was, designed to generate preliminary epidemiological information on TB in Gambella town and its surroundings southwestern Ethiopia.

\section{METHODS}

\section{Study area}

The study was conducted in Gambella Peoples National Regional State, Gambella town. The region is located in the Southwestern part of Ethiopia and borders two other regions, Oromia region to the North and east and the Southern Nations, Nationalities and Peoples' Regional State to the south and South Sudan to the west. Gambella is a name for both the region and the city, which is located about 753kilo meters West of Addis Ababa perched at an elevation of 526meters above sea level. The town is founded on the banks of the Baro River, Ethiopia's widest and the only navigable river. Gambella town is located inside the boundary of the Gambella Zuriya woreda, which again this is bordered on the south by the Abol Woreda, on the North and East by Oromia Regional state, on the West by Itang woreda (Figure 1).

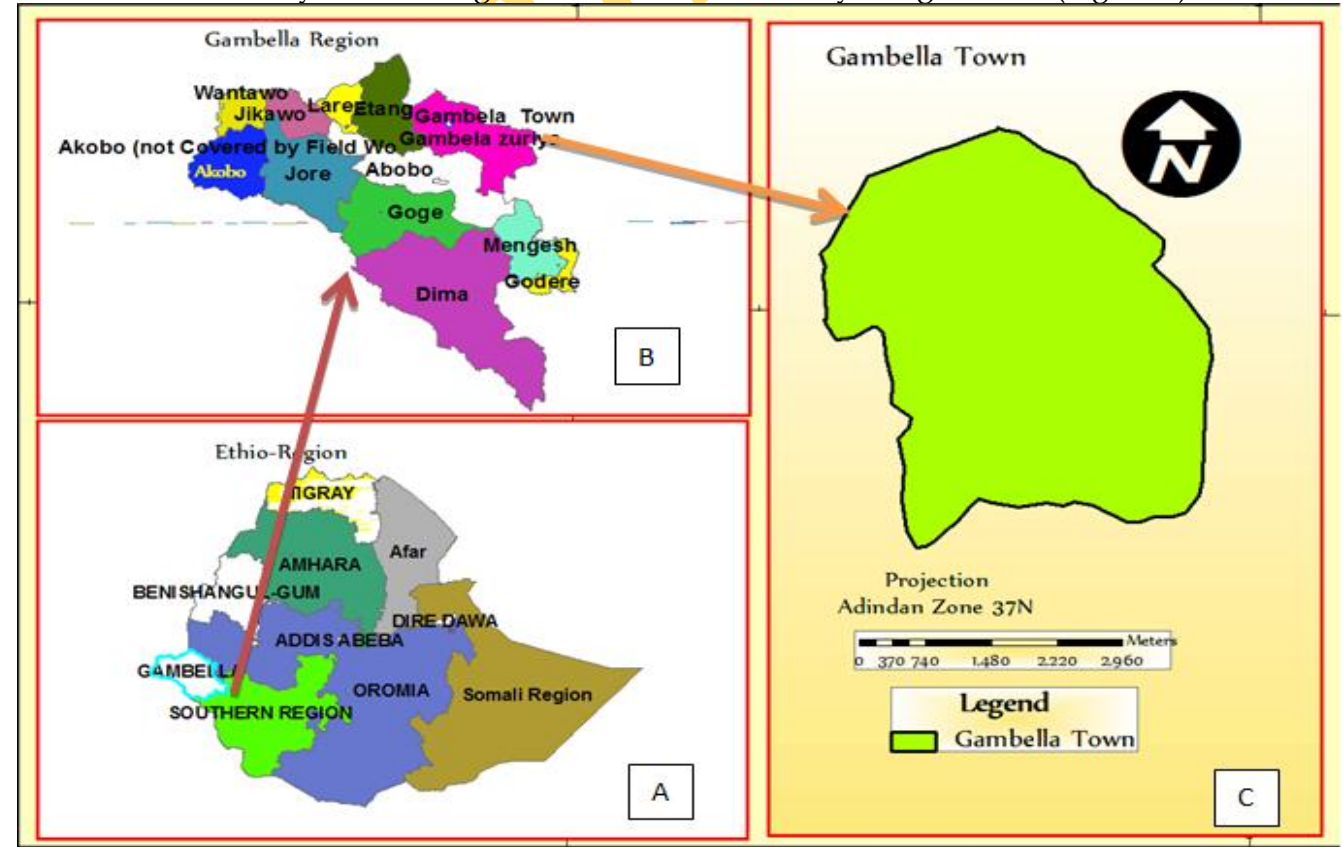


Figure 1. Map of study area.This map indicates the study area, A) Map of Ethiopia B) Gambella Regional state C) Gambella town located inside the Gambella Zuriya woreda. (Source: Designed by ArcGIS arc map 10 software based on the CSA 2007 data of Ethiopia by region)

\section{Retrospective data analysis}

TB registry Casebooks of Gambella Regional Hospital used to assess the situation of TB from 2003 to 2012 in Gambella Town and its surroundings. Variables such as forms of TB, sex, age pattern, patient type and as well as TB and HIV co-infection were assessed.

\section{Ethical Consideration}

The study was ethically cleared by the Institutional Ethical Clearance Committee, Aklilu Lemma Institute of Pathobiology, Addis Ababa University. After the detailed purpose of the study was explained to each presumptive patient and those voluntary to participate in the study are confirmed their willingness by giving their oral or written consent.

Ethical clearance was obtained from Addis Ababa University, Aklilu Lemma Institute of Pathobiology Institutional Review Board. A working permit was also obtained from Gambella Regional State Health Bureau.

\section{Statistical Analysis}

All data were analyzed by using Stata version 11.0 and Microsoft Excel. Descriptive statistics were used for analysis and expression of the result. Chi-square tests were used to compare differences between groups, and comparisons (difference) at $p<0.05$ were considered as statistically significant in this study.

\section{RESULTS}

A total of $4300 \mathrm{~TB}$ patients were registered for the last 10 years and treated in Gambella Regional Hospital. The sex proportion of male TB patients' was $56.51 \%$ (2430/4300). The mean and the standard deviation of age was $24.8 \pm 14$. 19. TB most frequently affected age group between 15-44 years in both sexes in both types of TB (PTB and EPTB) 2918 (67.86\%) followed by 0-14 years of age 957 (22.26\%).

From the 4300 TB cases registered in the last ten years, $1045(24.30 \%)$ of them were extra pulmonary tuberculosis cases and the rest $3255(75.70 \%)$ were pulmonary tuberculosis cases. Out of 4300 TB cases registered during the ten years, $2430(56.51 \%)$ were males $(\chi 2=3$. 35; $p>0.05)$. The annual trends of TB for both sexes were gradually declined in the last ten years.

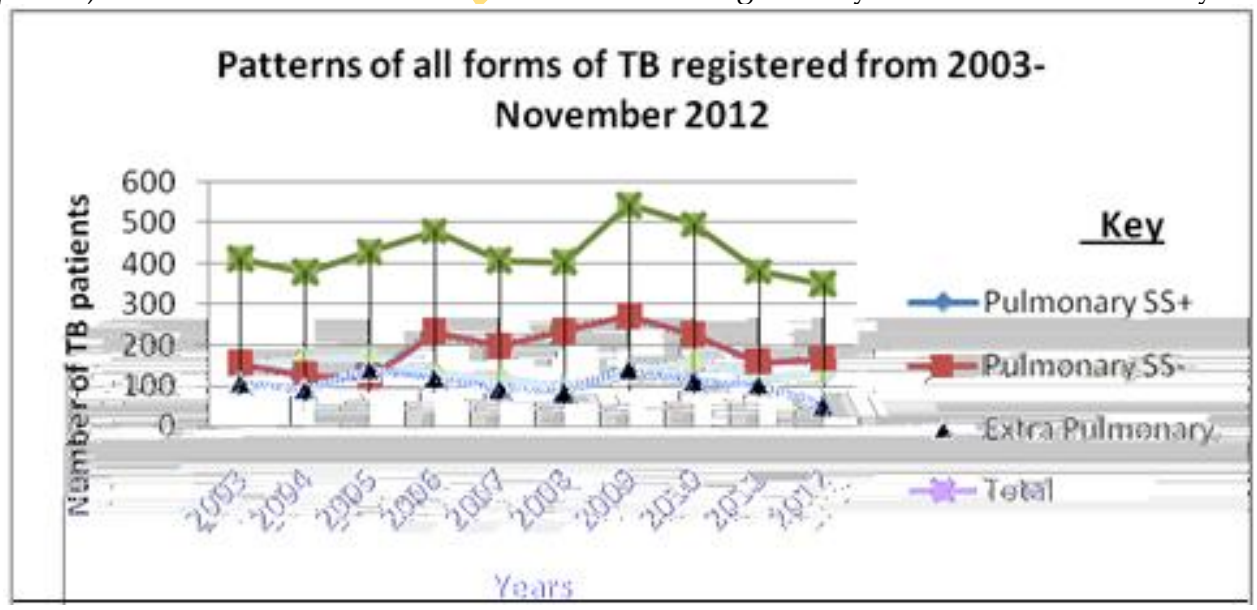


Figure 2: All forms of TB registered from1 ${ }^{\text {st }}$ January 2003 on 14 November 2012 in Gambella Regional Hospital. Briefly, the total TB trend shows as it decreases compared 2012 with 2003 yet there were slight variation along the ten years indicating that it was high in the year 2006 and 2009; smear negative cases were higher comparatively with other TB types even showed no declining manner along the ten years while extra pulmonary TB was showing variation in the magnitude ultimately drops below the level of the starting point.

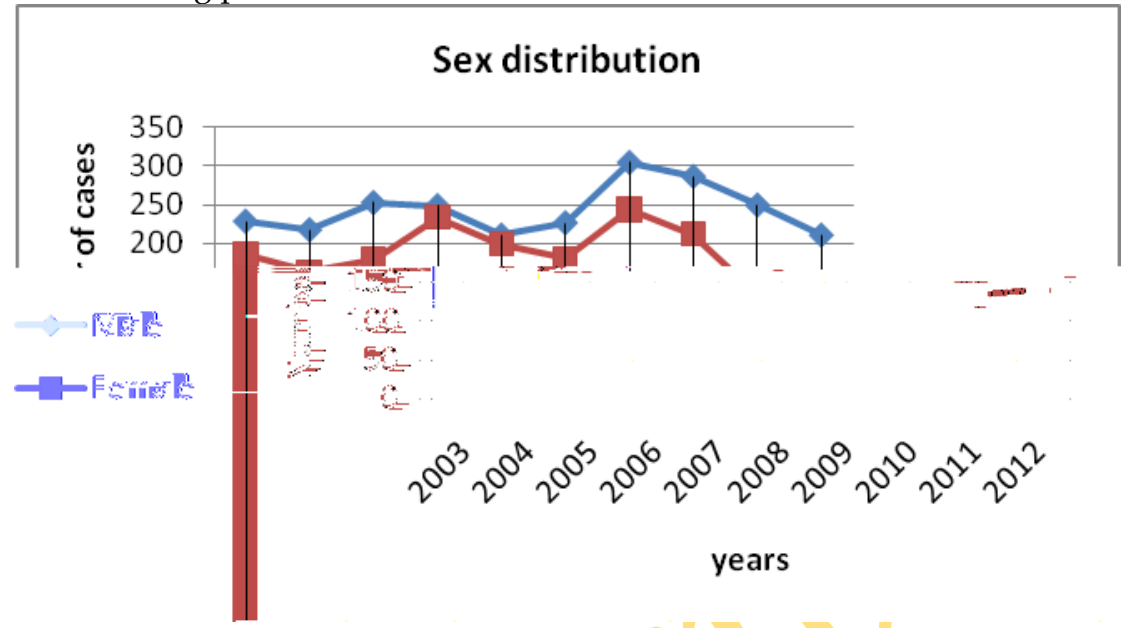

Figure 3.Sex distribution among TB patients from 1 $1^{\text {st }}$ January 2003 to 14 November 2012 in Gambella Regional Hospital, Gambella Town. The blue line indicates the trend of male sex along the ten year with a fluctuation of ups and downs while showed significantly higher in the year 2005-2006 and 2009 compared to the other years. Similarly the red line shows trend of females which is higher in frequency in the year 2006 and 2009.

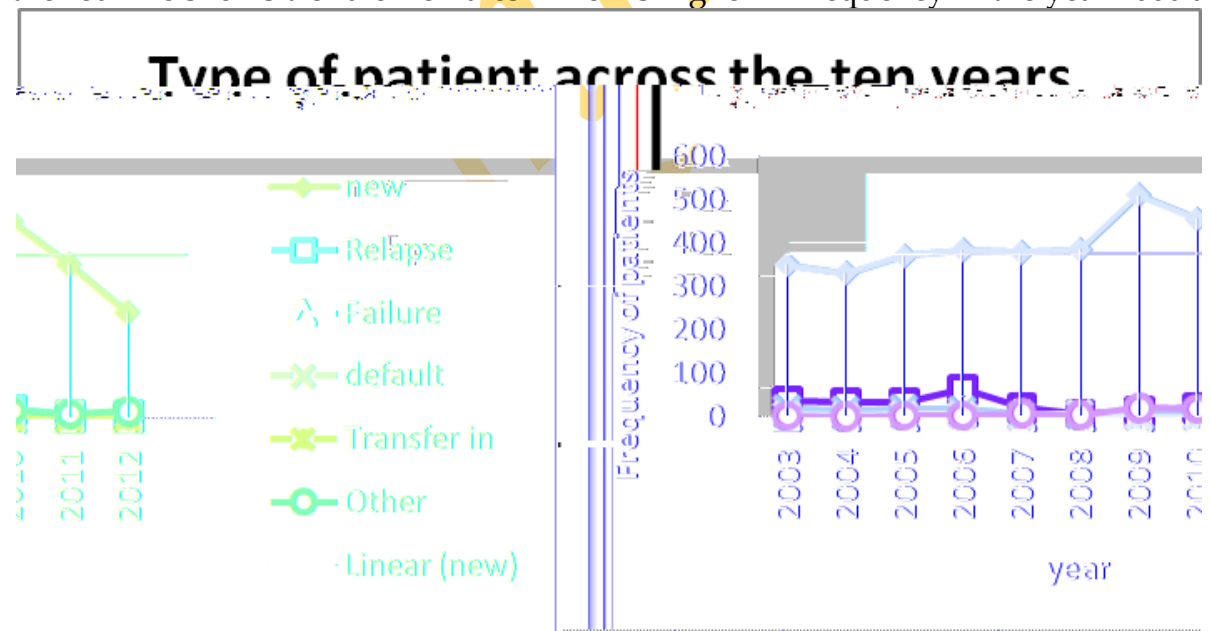

Figure 4.Type of TB patients registered from $1^{\text {st }}$ January 2003 to 14 November 2012 at the Gambella Regional Hospital, Gambella Town. The blue line on the top shows the frequency of new patients along the ten years, which is higher of all types, significantly in the year 2009. The yellow line indicates relapse cases, higher in the year of 2006 while it showed a declining situation towards the end of the $10^{\text {th }}$ year. The default and failure, in 
rose and black line respectively also are in a declining manner. Other shows categories, such as smear negative or extra pulmonary cases who are returning after default or who have recurrent disease, only sputum-positive patients can give the treatment regimen.

Table 1. Proportions of patient related variables with TB category from $1^{\text {st }}$ January 2003 to 14 November 2012 at the Gambella Regional Hospital.

\begin{tabular}{|c|c|c|c|c|c|c|c|}
\hline \multirow[t]{2}{*}{ Variable } & \multicolumn{4}{|c|}{ TB category $n(\%)$} & \multirow[b]{2}{*}{ Total } & \multirow[b]{2}{*}{$\chi^{2}$} & \multirow[b]{2}{*}{ p-value } \\
\hline & & PSPF & PSNF & EXPF & & & \\
\hline Sex & $\mathrm{N}=4300$ & & & & & & \\
\hline Male & & 837 (34.4) & $1028(42.30)$ & $565(23.25)$ & $2430(100.00)$ & 17.86 & 0.000 \\
\hline Female & & $531(28.40)$ & $859(45.94)$ & $480(25.67)$ & 1870(100.00) & & \\
\hline Total & & $1368(31.81)$ & 1887(43.88) & $1045(24.30)$ & $4300(100.00)$ & & \\
\hline Age category & $N=4300$ & & & & & & \\
\hline $0-14$ & & $75(7.84)$ & $461(48.17)$ & $421(43.99)$ & $957(100.00)$ & 449.99 & 0.000 \\
\hline $15-44$ & & $1164(39.89)$ & $1200(41.12)$ & 554(18.99) & $2918(100.00)$ & & \\
\hline $45-64$ & & $121(31.35)$ & $204(52.85)$ & $61(15.80)$ & $386(100.00)$ & & \\
\hline$>=65$ & & $9(23.08)$ & $30(76.92)$ & $9(23.08)$ & $39(100.00)$ & & \\
\hline Total & & $1368(31.81)$ & $1887(43.88)$ & $1045(24.30)$ & $4300(100.00)$ & & \\
\hline Residential area & $N=1800$ & & & & & & \\
\hline Rural & & $18(27.27)$ & $32(48.48)$ & $16(24.24)$ & $66(100.00)$ & 0.82 & 0.66 \\
\hline Urban & & 565 (32.58) & $786(45.33)$ & $383(22.09)$ & $1734(100.00)$ & & \\
\hline Total & & $583(32.39)$ & $818(45.44)$ & $399(22.17)$ & 1800(100.00) & & \\
\hline Patient type & $N=4300$ & & & & & & \\
\hline New & & $1171(30.67)$ & $1665(43.61)$ & $982(25.72)$ & $3818(100.00)$ & 182.41 & 0.000 \\
\hline Relapse & & $123(52.34)$ & $100(42.55)$ & $12(5.11)$ & $235(100.00)$ & & \\
\hline Failure & & $5(27.78)$ & 2 (11.11) & 11(61.11) & 18(100.00) & & \\
\hline Default & & $60(57.14)$ & $39(37.14)$ & $6(5.71)$ & $105(100.00)$ & & \\
\hline Transfer in & & $6(16.22)$ & $13(35.14)$ & $18(48.65)$ & $37(100.00)$ & & \\
\hline Other & & $3(3.45)$ & $68(78.16)$ & $16(18.39)$ & $87(100.00)$ & & \\
\hline Total & & $1368(31.81)$ & 1887(43.88) & $1045(24.30)$ & $4300(100.00)$ & & \\
\hline HIV status & $N=1444$ & & & & & & \\
\hline Positive & & $126(29.79)$ & $228(53.90)$ & $69(16.31)$ & $423(100.00)$ & 6.43 & 0.011 \\
\hline Negative & & 347 (33.99) & 447 (43.78) & $227(22.23)$ & $1021(100.00)$ & & \\
\hline Total & & $473(32.76)$ & $675(46.75)$ & $296(20.50)$ & 1444(100.00) & & \\
\hline
\end{tabular}

$\mathrm{N}=$ individuals with complete information; $\mathrm{PSPF}=$ pulmonary smear positive form, $\mathrm{PSNF}=$ pulmonary smear negative, $\mathrm{EXPF}=$ extra pulmonary form of $\mathrm{TB}, \chi^{2}=$ Pearson's chi square

\section{Discussion}

TB has long been recognized as a major public health problem since the 1950s worldwide. By considering the impact WHO initiated implementation of DOTS strategy in the 1990s to minimize the problem, yet, it ignited by the HIV / AIDS epidemic, still remains a major health problem in Ethiopia and other developing countries (WHO, 2005). This study used 10 years TB retrospective data to analyze the TB pattern in the area.

In this study, it was observed that males comprise the higher proportion of TB compared to females. (Shargie and Lindtjorn, 2005;Imam and Oyeyi, 2008; Datiko and Lindtjørn, 2009; Jetan et al., 2010; Berhe et al., 2012; Ejeta et al., 2012; Biadglegne et al., 2013).

Age groups of 15-44 years were affected more than the other age groups, which is consistent with WHO (2012) report. This is also is in agreement with the reports of other previous studies (Shargie and Lindtjorn, 2005; Imam and Oyeyi, 2008; Datiko and Lindtjørn, 2009; Tessema et al., 2009; Jetan et al., 2010; Ejeta et al., 2012; Prakasha et al., 2012; Biadglegne et al., 2013). This may be due to the fact that this age group is sexually active 
and hence infected with HIV, which predispose this group to TB. The proportions of the different types of TB recorded in were similar with those reported (Kassu et al., 2007; Tessema et al., 2009; Biadglegne et al., 2013). On the other hand, lower proportions were reported from India (Chakraborty, 2004). The proportion of smear positive TB recorded by the present study was similar with that of the Ethiopian national prevalence (WHO, 2012). It also showed that most of the cases were smear negative and co-infected with HIV.

The overall fall of annual distribution of all forms of TB registered cases in this study is in agreement with other studies (Lobato et al., 2006), in Japan (Shimao, 2009) and the countries profile (WHO, 2012). The probable reasons of falling down may be due to continuous implementation of DOTS, increased availability of health facilities and health service delivery increment and increased awareness by the public about the disease in the area (Yun et al., 2011).

currently, due to DOTS program implementations in the study area the relapse and defaulters cases were generally in a decreasing manner per years in responding to the program, which was similar to other studies done in south Ethiopia (Shargie and Lindtjorn, 2005), in northwestern shewa (Seyoum, 2007), in western Ethiopia (Ejeta et al., 2012) and in Jijiga district (Mohammed, 2007) yet these studies showed increased observations of relapse cases contrary to the present study. Thus, this decreasing in the observation of relapse cases may show the low drug resistance strain circulation in the area.

The proportion of TB in HIV positive individuals was found to be $29.29 \%$ in this study, which is higher than the national incidence $(6.3 \%)$, according to the WHO report (WHO, 2008). This high proportion of TB and HIV co-infection in area may be due to the high $\mathrm{HIV} / \mathrm{AIDS}$ dissemination that would have the effect on TB development.

\section{REFERENCES}

Berhe G, Enquselassie F, Aseffa A: Treatment outcome of smear-positive pulmonary tuberculosis patients in Tigray Region, Northern Ethiopia. BMC Public Health 2012, 12:537 doi: 10.1186/1471-2458-12-537.

Biadglegne F, Anagaw B, Debebe T, Anagaw B, Tesfaye W, Tessema B, Rodloff AC, Sack U: A retrospective study on the outcomes of tuberculosis treatment in FelegeHiwot Referral Hospital, Northwest Ethiopia. Inte J Medi and Med Scie 2013, 5(2), pp. 85-91.

Chakraborty AK: (2004): Epidemiology of tuberculosis: Current status in India. Review article, Indian J Med Res, 120, pp 248-276.

CSA: Central Statistics Agency of Ethiopia 2012, Addis Ababa Ethiopia.

Datiko DG, Lindtjørn B: Tuberculosis recurrence in smear-positive patients cured under DOTS in southern Ethiopia: retrospective cohort study. BMC Public Health, 2009, 9:348 doi: 10.1186/1471- 2458-9-348.

Dye C, Watt CJ, Bleed DM, MehranHosseini S, Raviglione MC: Evolution of tuberculosis control and prospects for reducing tuberculosis incidence, prevalence, and deaths globally. JAMA 2005, 293: 2767-75.

Ejeta E, Legesse M, Ameni G: Preliminary Study on the Epidemiology of Tuberculosis in Nekemte and Its Surroundings -Western Ethiopia. STAR, Jan-March 2012, 1(1): 18-25.

Harries AD, Dye C: (2006): Tuberculosis. Ann Trop Med Parasitol 2006, 100(5-6):415- 431.

Imam TS, Oyeyi TI: A Retrospective Study of Pulmonary Tuberculosis (PTB) Prevalence amongst Patients Attending Infectious Diseases Hospital (IDH) In Kano, Nigeria. Bayero. J Pure and App Scie 2008, 1(1):10 - 15.

Jetan CA, Jamaiah I, Rohela M, Nissapatorn M: Tuberculosis : An Eight Year (2000-2007) Retrospective Study at the University of Malaya Medical Centre (UMMC), Kuala Lumpur, Malaysia. Tuberculosis in Malaysia 2010, 2 (41): 378-385.

Kassu, A., Mengistu, G., Ayele, B., Diro, E., Mekonnen, F., Ketema, D., Moges, F., Mesfine, T., Getachew, A., Ergicho, B., Elis, D., Aseffa, A., Wondmikun, Y., and Ota, F. (2007): Co-infection and clinical manifestation of tuberculosis in human immunodeficiency virus -infected and -uninfected adults at $\mathrm{S}$ teaching hospital, North West Ethiopia. J Microbiol, immunol and Infect, 40: 116-122. 
Lobato MN, Wang Y, Becerra J, Simone P, Castro K: Improved Program Activities are Associated with Decreasing Tuberculosis Incidence in the United States. Public Health Rep 2006, 121(2): 108-115.

Mohammed I: Preliminary study on tuberculosis in Jijiga district, Eastern Ethiopia, MSc thesis, Aklilue Lemma Institute of Path biology 2007, Addis Ababa University, Ethiopia.

Palomino J C, Leão SC, Ritacco V: Tuberculosis 2007. From basic science to patient care TuberculosisTextbook.com $1^{\text {st }}$ edition 2007.

Prakasha RS, Suresh G, D'sa PI, Kumar GS, Rao R, Shetty M: A study of clinical characteristics and trend of different types of tuberculosis in coastal South India. Anna Trop Med and Public Health 2012, 5 (5): 489 494.

Seyoum T S: Study on tuberculosis in North Western Shewa, Central Ethiopia, M.Sc thesis, Aklilue Lemma Institute of Path biology 2007, Addis Ababa University, Ethiopia.\

Shargie BE, Lindtjorn B: DOTS improves treatment outcomes and services coverage for tuberculosis in Ethiopia: a retrospective tend analysis. Bio Med Center Public Health, 2005, 5: 62-73.

Shimao T: Tuberculosis prevalence survey in Japan. Kekkaku IB 2009, 84(11):713-20.

Tessema B, Muche A, Bekele A, Reissing A, Emmrich F, Sack U: Treatment outcome of tuberculosis patients at Gondar University Teaching Hospital, Northwest Ethiopia. A five-year retrospective study. BMC Public Health 2009, 9:371 doi: 10. 1186 / 1471-2458-9-371.

WHO: Global Tuberculosis Control Epidemiology, Strategy, Financing. WHO/HTM/TB/ 2009.4112009 , Geneva, Switzerland.

WHO: Global Tuberculosis Control. Surveillance, Planning, Financing. WHO Report 2005: World Health Organization. WHO/HTM/ TB/2005.349.Geneva, Switzerland

WHO: World Health Organization, WHO tuberculosis fact sheet No. 104 2012, Geneva, Switzerland

WHO: Global tuberculosis control: surveillance, planning, financing: WHO report 2008: (WHO/HTM/TB/2008.393).

Yun Lo H, Chou P, Yang S, Lee C, Kuol H: Trends in Tuberculosis in Taiwan, 2002-2008. J Formos Med Assoc 2011, 110(8):501-510.

\section{CALl for Paper}

ABC Journal of Advanced research (ABC-JAR) is an open-access, peer-reviewed multidisciplinary journal which seeks articles from any discipline of education. ABC-JAR features reports on current developments in advanced research as well as on related discipline issues. The digital online version is published by ABC-JAR home, ABC USA and the hard copy (print) version is published by $A B C$, Bangladesh. Web: www.abcjar.us
Engineering International (EI) is a peer-reviewed multi-disciplinary international journal devoted to academic advanced research from all aspects of engineering arena. It specializes in the publication of comparative thematic issues as well as individual research articles, review essays, and book reviews. Engineering International is fully and freely accessible on line. Web: www.j-ei.us 


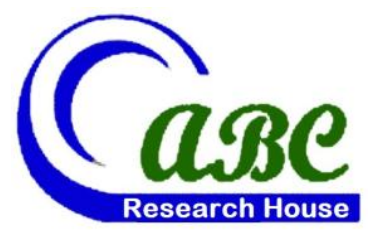

- Pantidalam, Kuala Lampur, Malaysia

- Rd 4, Shyamoli, Dhaka-1207, Bangladesh

- 3900 Woodhue Place, Alexandria, VA 22309, USA

www.abcreorg.weebly.com / www.abcjournals.net

Asian Business Consortium (ABC) is a multi-disciplinary research, training, publishing, digital library supporting and service house. Though founded in 2010 as the Business and Computing organization of Asia, it was reconstituted as the ABC in 2011. It has been working for creating and nurturing talents in USA, Malaysia and Bangladesh since its inception. As ABC is going global, it intends to open chapters in Australia, Germany, Japan, Pakistan, and other Asian countries in near future. The objectives of consortium are solely centered round the welfare and humane attitude of the founders who enthusiastically took up this noble cause and materialized it with a view to promote research and educational activities for the encouragement of scholars to develop their knowledge, to publish their analysis oriented scientific researches in international Journals, books, the task of organizing workshops, seminars, conferences, training, personality development programs and allied services.

In addition to research activities, ABC provides a good number of scholarships to the poor and meritorious students at various levels of education throughout the world. It plays an important role in the field of research by funding research projects and publishing the research papers. This consortium will unquestionably become the mouth-piece of the dark horses and unacknowledged scholar whose endowed and commendable contributions shall be provided an outlet keeping in mind the greater good of the larger society of the world.

$\mathrm{ABC}$ runs the following international referred journals for creating a platform to share the thoughts of professionals, scholars and academicians throughout the world.

\section{ABC Publications (ABC Journals)}

- Asian Accounting and Auditing Advancement (4A Journal)

- Asian Business Review (ABR)

- Asian Journal of Applied Sciences and Engineering (AJASE)

- Global Disclosure of Economics and Business (GDEB)

- $\quad$ ABC Journal of Advanced Research (ABC-JAR)

- International Journal of Reciprocal Symmetry and Theoretical Physics (IJRSTP)

- American Journal of Trade and Policy (AJTP)

- Asian Journal of Humanity, Art and Literature (AJHAL)

- Malaysian Journal of Medical and Biological Research (MJMBR)

- Asia Pacific Journal of Energy and Environment (APJEE)

- $\quad$ Engineering International (EI)

- $\quad$ ABC Research Alert (Online)

Each journal home page provides specific information for potential authors and subscribers. Open access policy, the quick review process, rich editorial boards and quality publications have already made $A B C$ Journals unique. ABC Journals are published under the direct supervisions of renowned academicians of the world.

Collaboration in Conference: ABC considers high-quality conference papers for publication. Please contact us for detailed information.

Collaboration in Publishing: If you like to start writing a book, propose a new journal or advertise in $\mathrm{ABC}$ journals, please feel free to contact us. 